\title{
The Clinical Predictive Value of the Neutrophil to Lymphocyte Ratio as a Biomarker in Lumbar Disc Herniation
}

\author{
Ali Yılmaz ${ }^{1}$ Hilal Altaş ${ }^{2}$ Timur Yıldırım ${ }^{1}$ Şükran Kaygısız ${ }^{3}$ Hasan Serdar Işık ${ }^{1}$ \\ ${ }^{1}$ Department of Neurosurgery Ordu University Medical School, Ordu, Turkey \\ ${ }^{2}$ Department of Radiology Ordu University Medical School, Ordu, Turkey \\ ${ }^{3}$ Department of Neurology Ordu University Medical School, Ordu, Turkey
}

Received: 20 July 2019, Accepted: 28 July 2019, Published online: 28 August 2019

(C) Ordu University Institute of Health Sciences, Turkey, 2019

\begin{abstract}
Objective: Low back pain is a frequently seen problem in the society and causes loss of labor. Although etiology of lumbar disc herniation is multi-factorial it is known that intervertebral disc degeneration is an important determinant for herniation. In recent studies, inflammatory mediators and inflamation itself has an efficient role in the degeneration process. We aimed to investigate the association between the neutrophil to lymphocyte ratio level as an inflammatory biomarker in patients with lumbar disc herniation.

Methods: 394 patients between the age of 18-80 applying to our center because of low back pain complaint and having lumbar MR were included in the study. The patients were divided into two groups as having lumbar disc hernia and not having based on the lumbar MR result. Blood samples were taken from all patients during application and neutrophil lymphocyte rates were calculated.

Results. Average age of group with lumbar disc hernia was 46 and 55 of these cases were female and 45 of them were male. $\mathrm{N} / \mathrm{L}$ rate was measured as $3.81+/-1.85(\mathrm{p}=0.001)$ in the group having lumbar disc hernia and significant difference compared to the control group was noted. It was found out that lifting weight $(\beta=0.12195 \% \mathrm{Cl}(0.052-0.281), \mathrm{P}<0.001), \mathrm{BMI}(\beta=0.226,95 \% \mathrm{Cl}(0.080-0.640) \mathrm{P}=0.005), \mathrm{DM}$ $(\beta=0.26895 \% \mathrm{Cl}(0.074-0.969), \mathrm{P}=0.045)$, smoking $(\beta=3.22695 \% \mathrm{Cl}(1,343-7.749), \mathrm{P}<0.009)$, educational background $(\beta=5.26895 \% \mathrm{Cl}(1.941-9.796), \mathrm{P}=0.001)$ and $\mathrm{NLR}(\beta=1.30295 \% \mathrm{Cl}(1.013-1.673), \mathrm{P}=0.039)$ were the independent predictors in the presence of lumbar disc herniation.
\end{abstract}

Conclusion: NLR may be used as a simple and reliable premise independent predictor of lumbar disc herniation in patients with low back pain.

Key words: Neutrophil to Lymphocyte Ratio, Back Pain, Lumbar Disc Herniation

Suggested Citation: Yılmaz A, Altaş H, Yıldırım T, Kaygısız Ş, Işık HS. The Clinical Predictive Value of the Neutrophil to Lymphocyte Ratio as a Biomarker in Lumbar Disc Herniation. Middle Black Sea Journal of Health Science, 2019; 5(2):145-150

\section{Address for correspondence/reprints:}

Ali Yılmaz

Telephone number: +90 (452) 2252342

E-mail: draliyilmaz19@gmail.com

DOI: $10.19127 / \mathrm{mbsjohs.594555}$

\section{Introduction}

Low back pain is a frequently seen problem in the society and causes loss of labor and significant burden on both the healthcare system and the economy. Its life-long prevalence is about $80 \%$ and rate of application to the hospital in adult population annually is $15 \%$ (Sarı et al.,2015).Lumbar disc herniation frequently occurs as a result of tear of annulus fibril not resisting to torsional forces in the end of degeneration and nucleus becomes herniated. (Boden SD et al., 1990).Although etiology of lumbar disc herniation is multi-factoral it is known that it is determinant 
for the etiology of intervertebral disc degeneration and herniation (Andersson GB et al., 1999; Shen FH et al., 2006).In recent studies, it has been shown that in addition to mechanical effects on lumbar disc degeneration and herniation, extended inflammation and inflammatory cytokine (such as tumor necrosis factor (TNF)- $\alpha$ and interleukin (IL)-1 $\beta$ ) has had efficient role for lumbar disc degeneration and herniation (Karin W et al., 2013; Wei Li et al., 2014).

Previously, Neutrophil-to-lymphocyte ratio (NLR), known to be a systemic inflammatory marker, has been shown to play a role in the progression of many diseases and it was shown that it has a prognostic value in many acute and chronic diseases (Kaya A et al., 2014). NLR is measured by proportioning 2 inflammatory markers (neutrophil and lymphocyte), it has a stronger predictive value (Kaya A et al., 2014).

Although it was shown that predictive value of increased NLR in many diseases, the relationship between NLR and lumbar disc herniation has not been investigated comprehensively. Therefore, in this particular study, we aimed to investigate the association between the NLR level and lumbar disc herniation in patients with low back pain.

\section{Method:}

\section{Study population}

This was a case-control study whose subjects were sampled from neurosurgery department of our hospital. 394 patients (between the age of 1880) applying to our center for low back pain complaint between the dates of September 2015 and January 2018 were included in the study.

Exclusion criteria were previous lumbar surgery (n: 42), epidural corticosteroid injection within the last 6 months (89), known inflammatory condition (n:51) (e.g. vasculitis, seronegative arthritis, rheumatoidarthritis, systemic lupuserythematosus, gout, osteomyelitis, discitis,buruselloz, pot disease), history of cancer (n:11) and pregnancy (n:2) respectively. Finally 199 patients were included in the study. Patients were divided into two groups as patients having discopathy and having normal lumbar MR results based on the MRI results. Lumbar MRI of selected patients examined by a neurosurgeon and a neuroradiolog.

Written informed consent was received from all patients, and the study protocol was approved by the hospital's local ethics committee Ordu University (70/04.05.2018) in accordance with the Helsinki Declaration and Good Clinical Practice
Guidelines.

\section{Definitions}

Discopathy was defined;

1) Protrusion: $<\% 25$ of disc circumferences, base wider than herniation

2) Extrusion: Complete annular tear with passage of nuclear material beyond disc annulus, base narrower than herniation dome, disc material may extend above or below endplates or adjacent intervertebrae

3) Sequestered: Disc material that has no continuity with the parent disc and is displaced away from the site of extrusion. It corresponds to a subtype of disc extrusion (Spengler DM et al., 1990).

DM: When use of anti-diabetic medicine was in question or post-prandial blood sugar was above $200 \mathrm{mg} / \mathrm{dl}$ in any time or fasting plasma glycose was minimum $126 \mathrm{mg} / \mathrm{dl}$, diagnosis of diabetes was established.

\section{Laboratory Data}

Blood samples were taken from patients that were admitted to our Neurosurgery Department with the complaint of low back pain for the whole blood count and the biochemistry parameter measurement. Blood samples were collected from the antecubital vein by and a traumatic puncture and were sent to the laboratory for analysis within 1 hour after collection. Hemoglobin, total WBC, neutrophils, lymphocytes, and monocytes were determined by an automated blood cell counter calledCoulter LH 780 Hematology Analyzer (BeckmanCoulterIrelandIncMervue, Galway, Ireland). Biochemical parameters were measured during the Abbott Architect C16000 autoanalyzer (Abbottlaboratories, Abbott park, IL, USA).

\section{Statistical Analysis}

The data analysis was conducted using SPSS (version 20.0, SPSS Inc., Chicago, IL, USA) and MedCal statistical software (trial version 12.7.8, Mariakerke, Belgium). Continuous variables data are expressed as the mean \pm standard deviation. Categorical variables were compared using Chisquare or Fisher's exact tests and summarized as percentages. The Kolmogorov-Smirnov test was used to evaluate the distribution of the continuous variables. To predict lumbar disc herniation, gender, age, smoking, occupational motor vehicle driving, trauma history, heavy lifting, diabetes mellitus (DM), Neutrophil-lymphocyte ratio (N/L), and education status and body mass index (BMI) 
included in the univariate analysis. The parameters with $\mathrm{p}<0.05$ were included in the multiple logistic analyses. Receiver operating characteristic (ROC) curves were used to predict the future incidence of CIN.

\section{Results}

Average age of the group with lumbar disc herniation was 46 and 55 of cases in this group were females and 45 of them were males. Rates of motor vehicle driving was found as $30 \%$, trauma history was $31 \%$, heavy lifting was $74 \%$, smoking was $56 \%$ and DM rate was found as $27 \%$. N/L rate was measured as $3.81+/-1.85(\mathrm{p}=0.001)$ in the group having lumbar disc herniation and a significant difference compared to the control group as noted. Educational level in this group was $76 \%$ primary-secondary school and $\mathrm{BMI} \geq 30$ (obese) $33 \%$ and a significant difference was found compared to the control group $(\mathrm{p}<0.001)$. Clinical and laboratory characteristics of the groups are presented in Table 1

In multiple regression analysis, it was found out that heavy lifting $(\beta=0.12195 \% \mathrm{Cl}(0.052-0.281)$, $\mathrm{P}<0.001)$, BMI $\quad(\beta=0.226,95 \% \mathrm{Cl}(0.080-0.640)$ $\mathrm{P}=0.005), \mathrm{DM}(\beta=0.26895 \% \mathrm{Cl}(0.074-0.969)$, $\mathrm{P}=0.045)$,smoking $(\beta=3.226 \% 95 \mathrm{Cl}(1,343-7.749)$, $\mathrm{P}<0.009)$, educational background $(\beta=5.26895 \%$ $\mathrm{Cl}$ (1.941-9.796), $\mathrm{P}=0.001)$ and NLR $(\beta=1.302$ $95 \% \mathrm{Cl} \quad(1.013-1.673), \quad \mathrm{P}=0.039)$ were the independent predictors in the presence of lumbar disc hernia (Table 2 and Figure 1).

Table 1. Comparison of Disc herniation Group And Control Group

\begin{tabular}{|c|c|c|c|c|}
\hline & & $\begin{array}{c}\text { Lumbar } \mathrm{mr} \text { is } \\
\text { normal }\end{array}$ & $\begin{array}{l}\text { Lumbar disc } \\
\text { hernia }\end{array}$ & $\mathrm{P}$ value \\
\hline \multicolumn{2}{|l|}{ Sex, male $(\mathrm{n}, \%)$} & $21(21.9)$ & $45(45)$ & 0.001 \\
\hline \multicolumn{2}{|l|}{ Age (years) } & $42.99 \pm 13.77$ & $46.89 \pm 9.91$ & 0.025 \\
\hline \multicolumn{2}{|l|}{ Smoking } & $24(24,24)$ & $39(39)$ & 0.019 \\
\hline \multicolumn{2}{|c|}{ Motor vehicle driving (n, \%) } & $15(15.6)$ & $30(30)$ & 0.017 \\
\hline \multicolumn{2}{|c|}{ Trauma history $(\mathrm{n}, \%)$} & $14(14.6)$ & $31(32.3)$ & 0.004 \\
\hline \multicolumn{2}{|c|}{ Heavy lifting (n, \%) } & $24(24,24)$ & $74(74)$ & $<0.001$ \\
\hline \multicolumn{2}{|l|}{$\operatorname{Dm}(\mathrm{n}, \%)$} & $6(6.3)$ & $27(27)$ & $<0.001$ \\
\hline \multicolumn{2}{|l|}{$\mathrm{N} / \mathrm{L}$ rate } & $2.05 \pm 1.02$ & $3.81 \pm 1.85$ & 0.001 \\
\hline \multirow[t]{2}{*}{ Educational level } & Primary-secondary school & $40(41.7)$ & $76(76)$ & $<0.001$ \\
\hline & High school and above & $56(58.3)$ & $24(24)$ & $<0.001$ \\
\hline \multicolumn{2}{|l|}{$\mathrm{BMI} \geq 30(\mathrm{n}, \%)$} & $9(9.4)$ & $33(33)$ & $<0.001$ \\
\hline
\end{tabular}

Table 2. Evaluation of Independent Predictors of Disc herniation

\begin{tabular}{lll|lll}
\hline & \multicolumn{2}{l}{ Univariate analysis } & \multicolumn{3}{c}{ Multivarite analysis } \\
\cline { 2 - 6 } & QR & P value & beta & 95\% Cl & P value \\
\hline Sex (\% male) & 0.342 & 0.001 & & & \\
Age (years) & 1.042 & 0.025 & & & \\
Motor vehicle driving & 0.432 & 0.017 & & & \\
Trauma history & 0.452 & 0.004 & & & \\
Heavy lifting & 0.117 & $<0.001$ & 0.121 & $0.052-0.281$ & $<0.001$ \\
Dm & 5.548 & $<0.001$ & 0.268 & $0.074-0.969$ & 0.045 \\
N/L rate & 1.419 & 0.001 & 1.302 & $1.013-1.673$ & 0.039 \\
Education & 0.226 & $<0.001$ & 5.268 & $1.941-9.796$ & 0.001 \\
BMI & 4.761 & $<0.001$ & 0.226 & $0.080-0.640$ & 0.005 \\
Smoking & 3.818 & $<0.001$ & 3.226 & $1.343-7.749$ & 0.009 \\
\hline
\end{tabular}

\section{Discussion:}

In our study, we showed that NLR predict the lumbar disc herniation. It was found as an independent predictor of lumbar disc herniation.

Lumbar disc herniation is one of the pathologies occurring secondary to the degeneration frequently. This mechanism is in the form of tear of annulus fibril not resisting to torsional forces and deactivation of end platenucleus- annulus complex functioning as a closedsystem accordingly. By the effect of incoming compressive force, nucleus become herniated from torn annulus region and end-plate microfractures occur the contact of nucleus with spongiform bone and blood members in vertebra corpus results in immune reaction and trigger inflammatory process. In the end of degenerative processes, nucleus migrates towards the canal and causes stenosis or root pressure. This pressure results in radicular pain and clinical symptom (Parker SL et al., 2004; En'Wezoh DC et al., 2016). 


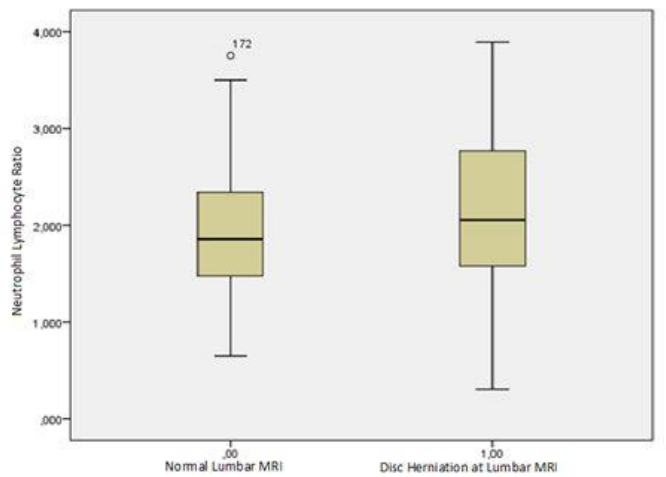

Figure 1: Comparison of mean NLR Between Control Group and in Disc Herniation Group

For the disc degeneration, genetic characteristics, environmental impacts and mechanical effects of heavy occupational conditions have been emphasized frequently. In the studies, it has been reported that dynamic and static loading might initiate the disc degeneration (Osterman H, et al., 2016; Shamji MF 1 et al., 2010). Similarly, end plato fracture is a significant factor for the onset of disc degeneration, high impact loading may deteriorate the natural matrix structure of disc tissue without end plate fracture have been shown on MRI scans (Stefan D et al., 2014).In our study, parallel with the studies in the literature, a significant relationship was found among motor vehicle driving, heavy lifting, trauma history and $\mathrm{BMI} \geq 30$ with lumbar disc herniation presence as related to dynamic and static loading. Similarly, a significant relationship was found between DM, age and sex of male with the presence of lumbar disc hernia in our study. It is also known that cell -mediated mediators such as interleukin and TNF are efficient for the onset and progress of disc degeneration (Adams MA et al., 2016; Singh K et al., 2006). There are studies in the literature showing that inflammatory process has an important role in the process of degeneration (Ala-Kokko L et al., 2005; .Battie' M et al., 2014).

Although the definite mechanism is not understood exactly, it is reported that there is a significant relationship between the degree of degeneration and levels of inflammatory mediators due to intervertebral disc pathology (Wei Li et al., 2014).It has been found out that inflammatory process increases cell aging and apoptosis and reduces disc anabolism and in this way, it inhibits expression of genes coding type II collagen and proteoglycan being the structural component of the intervertebral disc. Similarly, it has been shown that inflammatory process deteriorates the non- cellular matrix of intervertebral disc and facilitates catabolic processes and increases degeneration (LiW et al., 2014).

While effects of inflammation on disc generation are known, at which step it has a role and its role is not understood exactly. Whether the inflammation has an efficient role from the beginning of disc degeneration process or occurs as a result of changes due to mechanical effects or not should be evaluated with the new related studies in the future.

In chronic severe and continuous inflammation cases, number of neutrophil increases as secondary to the inflammation. Simultaneously, it contributes to the decrease of lymphocyte as a result of severe apoptosis and distribution of lymphocyte secondary to the stress inducing to lymphatic organs (Sen BB et al., 2014).

It is known that monocyte, lymphocytes and neutrophils being the while blood cell group have a critical role in inflammatory response. As it has been demonstrated in previous studies, following infiltration of stimulated macrophages, natural killer cells, lymphocyte and especially neutrophile to the tissue and excessive activation, release of many enzymes, cytokine, reactive oxygen products, protease, elastase (Harjai KJ et al., 2008; Russo D et al., 1995; Solomon R et al., 2010). All of these factors may contribute to disc degeneration by increasing damage of tissue.

In our study being compatible with the data of literature, a significant and independent relationship has been found between the rate of neutrophil-lymphocyte being an easy and fast detectable marker of systemic inflammation and presence of lumbar disc herniation. Presence of an independent correlation between these two parameters may be useful for taking protective actions for the individuals being at risk in terms of lumbar disc hernia. In the light of findings, it has been considered that NLR may be added to the diagnosis algorithm as a predecessor assistant marker in the risk group and initiation of antiinflammatory based medical therapies and conservative approaches in early period in cases with high NLR may have a protective role in disc degeneration and lumbar disc hernia development. For this reason, our findings are of clinical importance.

\section{Limitations}

This is an observational, single-institution study, which had a relatively small sample size and was thus subject to various unaccounted 
confounders inherent in such an analysis. Additionally, we could not compare N/L with other inflammatory markers, TNF alfa, interleukin, fibrinogen, or myeloperoxidase, because they were not routinely obtained in our study population.

\section{Conclusion}

In this study, it's determined that increased NLR is an independent predictor of lumbar disc herniation, which is as an easily applicable, simple and useful non-specific inflammatory marker. This finding is of clinical importance, since early initiation of anti-inflamatory-based preventive medical therapies and conservative therapies may provide time to prevent the progression of lumber disc herniation and improve its negative impact on outcome.

Ethics Committee Approval: Ethics committee approval was received for this study from Ordu Clinical Research Ethics Committee of ORDU University. Ethics no: 70/04.05.2018.

Peer-review: Externally peer-reviewed.

Author Contributions: Externally peer-reviewed. Author Contributions: Concept-Y.A., A.H., Design-Y.A., A.H., Supervision-Y.T., I.S.H., K.Ş., Literature Review- Y.A., A.H. Writing- Y.A., A.H., Critical Review- I.S.H.,

Conflict of Interest: No conflict of interest was declared by the author.

Financial Disclosure: The authors declared that this study hasn't received no financial support.

\section{References}

Andersson GB.Epidemiological features of chronic low-backpain.Lancet. 1999; 581-585.

Adams MA, Roughley PJ. What is intervertebral disc degeneration, and what tcauses it? Spine.2006;31(18):2151-2161.

Ala-Kokko L. Genetic risk factors for lumbar disc disease. Ann Med 2002;34 (1):42-47.

Battié MC, Videman T, Gibbons LE, Fisher LD, Manninen H, Gill K. et al. Volvo Award in clinical sciences: Determinants of lumbar disc degeneration. Spine 2005; 20 (24):2601-2612.

Boden SD, McCowin PR, Davis DO, Dina TS, Mark AS, Wiesel S. Abnormal magneticresonance scans of the lumbar spine in asymptomatic subjects. A prospective investigation. J Bon JointSurgAm. 1990;72(8):403-408.
En'Wezoh DC, Leonard DA, Schoenfeld AJ, Harris $\mathrm{MB}$, Zampini JM, Bono CM Effectiveness of micro discectomy for lumbardisc herniation: A randomized controlled trial with 2 years of follow-up. Spin.2016;31(6):2409-2414.

Harjai KJ, Raizada A, Shenoy C, Sattur S, Orshaw $\mathrm{P}$, Yaeger K,et al. A comparison of contemporary definitions of contrast nephropathy in patient sunder going percutaneous coronary intervention and a proposal for a novel nephron pathygrading system. Am J Cardiol 2008;101(6):812-819.

Karin W, Lisbet H. Inflammatory Mediators in Intervertebral disc degeneration and discogenic pain Global Spine J.2013;3(3):175-184.

Kaya A, Kaya Y, Topcu S, Gunaydin ZY, Kurt M, Tanboga IH, et al. Neutrophil-to Lymphocyte Ratio Predicts Contrast-Induced Nephropathy in Patients Undergoing Primary Percutaneou s Coronary Intervention. Angiology.2014;5(1): 51-56.

Kaya A, Kurt M, Tanboga IH, Isik T, Ekinci M, Aksakal E et al. Relation of neutrophil to lymphocyte ratio with the presence and severity of stable coronary artery disease. Clin Appl Thromb Hemost.2014;2(5):473-477.

LiW, LiuT, WuL, ChenC, JiaZ, BaiX, etal.Blockin $\mathrm{g}$ the function of inflammatory cytokines and $\mathrm{m}$ ediators by using IL-10 and TGF- $\beta$ : a potential biological immune therapy for intervertebral disc degeneration in a beagle model.nt J MolSci 2014;15(10):172183.

Osterman H, Seitsalo S, Karppinen J, Malmivaara A. Effectiveness of micro discectomy for lumbar disc herniation: A randomized controlled trial with 2 years of follow-up. Spin.2006;31(21):2409-2414.

Parker SL, Godil SS, Mendenhall SK, Zuckerman SL, Shau DN, McGirt MJ. Two-year comprehensive medical management of degenerative lumbar spine disease (lumbar spondylo listhesis, stenosis, or disc herniation) a value analysis of cost, pain, disability, and quality of life: clinical article. J Neurosurg Spine.2014;21(2):43-149.

Russo D, Minutolo R, Cianciaruso B, Memoli B, Conte $\mathrm{G}$ et al. Earlyeffects of contrast media on renal hemodynamics and tubular function in chronic renal failure. J Am Soc Nephrol 1995;6(5) :1451-1458. 
Sari S, Aydogan M, As a common cause of backpain: Lumbar disc herniation Sar1, Totbid Dergisi. 2015;14:298-304..

Sen BB, Rifaioglu EN, Ekiz O, Sen T, Celik E, Dogramaci AC. Neutrophil to lymphocyte ratio as a measure of systemic inflammation in psoriasis. Cutan Ocul Toxicol 2014;33(3) :223227.

Shamji MF, Setton LA, Jarvis W, So S, Chen J, Jing L et al. Proinflammatory cytokine expression profile in degenerated and herniated human intervertebral disc tissues. Arthritis Rheum.2010;62(7):1974.

Shen FH, Samartis D, Anderson GB. Nonsurgical management of acute and chronic low back pain. JAmAcad Orthop Surg.2006;4(14):477487.

Singh K, Masuda K, An HS. Animal models for human disc degeneration. Spine J. 2006;5(6) :267-279.

Solomon R, Dauerman HL. Contrast-induce dacute kidney injury. Circulation 2010;22(23):24512455.

Spengler DM, Ouellette EA, Battié M. Elective discectomy for herniation of a lumbar disc. Additional experience with an objective method. J Bone Joint Surg Am.1990;72(2): 230-237.

Stefan D, Daniel H, Stephen J. Fracture of the vertebral endplates, but not equienergetic 1mpact load, promotes disc degeneration in vitro. Journal of orthopaedic research 2012; 3(5):809-816. 